\title{
Comparison of priming versus slow injection for reducing etomidate- induced myoclonus: a randomized controlled study
}

\author{
Parul Mullick, Vandana Talwar, Shipra Aggarwal, Smita Prakash, and \\ Mridula Pawar \\ Department of Anaesthesia and Intensive Care, Vardhman Mahavir Medical College and Safdarjung Hospital, New \\ Delhi, India
}

\begin{abstract}
Background: Etomidate injection is often associated with myoclonus. Etomidate injection technique influences the incidence of myoclonus. This study was designed to clarify which of the two injection techniques-slow injection or priming with etomidate-is more effective in reducing myoclonus.

Methods: This prospective randomized controlled study was conducted on 189 surgical patients allocated to three study groups. Control group (Group C, $\mathrm{n}=63$ ) received $0.3 \mathrm{mg} / \mathrm{kg}$ etomidate (induction dose) over $20 \mathrm{~s}$. Priming group (Group $\mathrm{P}, \mathrm{n}=63$ ) received pretreatment with $0.03 \mathrm{mg} / \mathrm{kg}$ etomidate, followed after $1 \mathrm{~min}$ by an etomidate induction dose over $20 \mathrm{~s}$. Slow injection group (Group S, $\mathrm{n}=63)$ received etomidate $(2 \mathrm{mg} / \mathrm{ml})$ induction dose over $2 \mathrm{~min}$. The patients were observed for occurrence and severity of myoclonus for $3 \mathrm{~min}$ from the start of injection of the induction dose.

Results: The incidence of myoclonus in Group P (38/63 [60.3\%], 95\% CI: 48.0-71.5) was significantly lower than in Group C (53/63 [84.1\%], 95\% CI: 72.9-91.3, P = 0.003) and Group S (49/63 [77.8\%], 95\% CI: 66.0-86.4, P = 0.034). Myoclonus of moderate or severe grade occurred in significantly more patients in Group C (68.3\%) than in Group P (36.5\%, $\mathrm{P}<0.001)$ and Group $\mathrm{S}(50.8 \%, \mathrm{P}=0.046)$, but the difference between Groups $\mathrm{P}$ and $\mathrm{S}$ was not significant $(\mathrm{P}=0.106)$. Conclusions: Priming is more effective than slow injection in reducing the incidence of myoclonus, but their effects on the severity of myoclonus are comparable.
\end{abstract}

Keywords: Adverse effect; Etomidate; Injection method; Myoclonus.

Corresponding author: Parul Mullick, M.D.

Department of Anaesthesia and Intensive Care, Vardhman Mahavir Medical College and Safdarjung Hospital, 257, Sector A, Pocket C, Vasant Kunj, New Delhi 110070, India

Tel: 919810606262 , Fax: 911126163072

Email: parash93@yahoo.com

ORCID: https://orcid.org/0000-0003-4384-3377

Received: July 6, 2017.

Revised: September 6, 2017 (1st); November 6, 2017 (2nd); January 8, 2018 (3rd); February 22, 2018 (4th); March 8, 2018 (5th). Accepted: March 9, 2018.

Korean J Anesthesiol 2018 August 71(4): 305-310 https://doi.org/10.4097/kja.d.18.27168

\section{Introduction}

Etomidate is an imidazole derivative, that is widely used as an intravenous anesthetic induction agent. It causes minimal respiratory depression and does not induce histamine release. Being a cardio-stable drug, it is especially preferred in patients who are hemodynamically unstable. However, the use of etomidate may be associated with undesirable effects such as myoclonus. The incidence of etomidate-induced myoclonus (EIM) in unpremedicated patients is reported to be as high as $50-80 \%$ [1-3]. The myoclonic movements are not only disturbing [4] but may increase the risk of regurgitation and aspiration in non-fasted

(c) This is an open-access article distributed under the terms of the Creative Commons Attribution Non-Commercial License (http://creativecommons.org/ licenses/by-nc/4.0/), which permits unrestricted non-commercial use, distribution, and reproduction in any medium, provided the original work is properly cited. 
patients [5], and are detrimental in patients with open-globe injury [6]. Altering the speed of injection of etomidate [4] and pre-treatment with drugs such as lidocaine [7], midazolam [8], magnesium [9], fentanyl [10], and dexmedetomidine [11] have been investigated as ways of reducing EIM, with variable results.

A change in the etomidate injection technique can itself reduce the incidence of EIM, eliminating the need for an additional drug with its inherent cost and potential side effects $[2,4]$. Pre-treatment with a low dose of etomidate (priming dose) [2] and slow injection of the induction dose [4] have both been shown to reduce the incidence of EIM. To the best of our knowledge, however, there are no studies comparing these two techniques, and therefore it is not clear which is the better option. We, therefore, conducted this study to determine which of the techniques is more effective in reducing the incidence of myoclonus.

\section{Materials and Methods}

This prospective, randomized controlled study was conducted in the Department of Anesthesia and Intensive Care, Vardhman Mahavir Medical College and Safdarjung Hospital, New Delhi, India, after obtaining approval from the hospital ethics committee. The study was registered with the Clinical Trials Registry-India (CTRI/2015/02/005592).

The study was conducted from November 2013 to May 2015, on 189 patients ranging in age from 18 to 60 years, of both sexes, American Society of Anesthesiologists physical status classification I-II, scheduled for elective surgery under general anesthesia. The surgical procedures included general surgery, urosurgery, gynecological surgery, plastic surgery, and ear-nosethroat (ENT) surgery. Exclusion criteria were: pre-existing adre- nal disease or adrenocortical insufficiency; receiving or having a history of receiving steroids within the last three months; sepsis; hypersensitivity to the study drug; history of a seizure disorder; and neurological disease.

A total of 250 patients were assessed for eligibility. Of these, 61 patients were excluded, as 49 patients did not meet the inclusion criteria and 12 patients declined to participate. Finally, 189 patients were randomized into the three study groups, with 63 patients in each group (Fig. 1).

Patients were advised to fast for $6 \mathrm{~h}$ prior to surgery and were not given any premedication. Written informed consent was obtained from all patients after explanation of the risks and benefits of the study medication and the anesthesia technique.

Using a computer-generated random number table, patients were allocated randomly into three groups (63 patients in each group), the control group (Group C), priming group (Group P), and slow injection group (Group S). Concealment of allocation was done using sequentially numbered, opaque, sealed envelopes, which were numbered in advance and opened only after the participant's name and other details were written on the appropriate envelope.

In the operating room, standard monitors were applied (electrocardiogram, non-invasive blood pressure, and pulse oximeter) and baseline hemodynamic parameters were noted. Intravenous access was secured with an 18-gauge intravenous catheter. In Group P, patients received a priming dose of $0.03 \mathrm{mg} / \mathrm{kg}$ etomidate, followed after $1 \mathrm{~min}$ by an induction dose of $0.3 \mathrm{mg} / \mathrm{kg}$, injected manually over $20 \mathrm{~s}$. In Group S, patients received an induction dose of $0.3 \mathrm{mg} / \mathrm{kg}$ etomidate, injected slowly over $2 \mathrm{~min}$ using a syringe infusion pump. In Group C, patients received an induction dose of $0.3 \mathrm{mg} / \mathrm{kg}$ etomidate, injected manually over $20 \mathrm{~s}$.

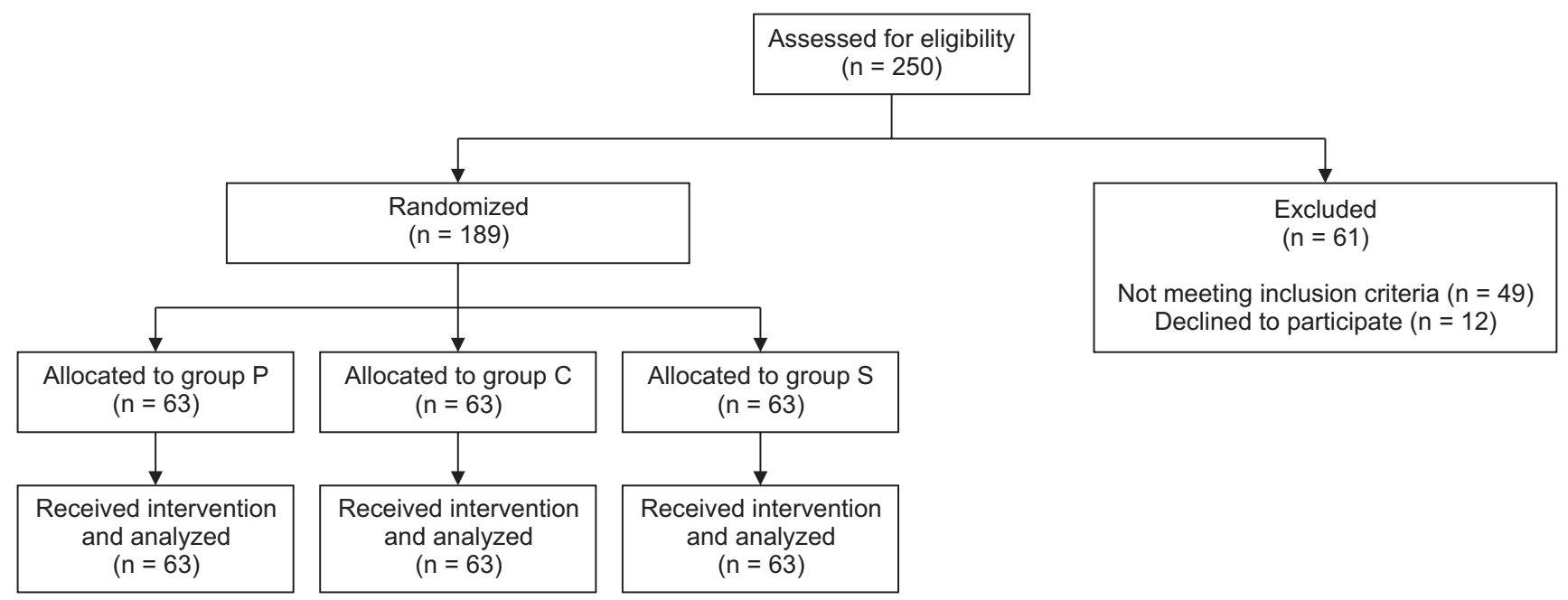

Fig. 1. CONSORT diagram for the study. Group P: priming group, Group C: control group, Group S: slow injection group. 
All patients were watched for the occurrence of myoclonus (primary endpoint) by an independent observer for $3 \mathrm{~min}$ from the start of injection of the induction dose of etomidate. The time of onset of myoclonus was noted and categorized as 'within $1 \mathrm{~min}$,' ' 1 to $2 \mathrm{~min}$, and ' 2 to 3 min' from the start of induction. The myoclonic movement was graded as 0 for no myoclonus, 1 for mild myoclonus (short movement of a body segment, e.g., a finger or wrist), 2 for moderate myoclonus (mild movement of two different muscle groups, e.g., face and arm), and 3 for severe myoclonus (intense myoclonic movement in two or more muscle groups or fast adduction of a limb) [4]. In case of difficulty in mask ventilation due to myoclonus, we planned to administer a neuromuscular blocking agent immediately. The time until loss of consciousness (LOC), defined as the time from start of injection of the induction dose of etomidate until loss of response to verbal commands (e.g., noncompliance when asked to open the eyes), was noted. The dose of etomidate administered when LOC was observed (LOC dose) was also noted.

Three min after the start of induction with etomidate, patients in all the groups were administered fentanyl $(2 \mu \mathrm{g} / \mathrm{kg})$ and vecuronium bromide $(0.1 \mathrm{mg} / \mathrm{kg})$ to facilitate tracheal intubation. Anesthesia was maintained with isoflurane in a mixture with oxygen and nitrous oxide. After completion of surgery, residual neuro-muscular blockade was antagonized with neostigmine and glycopyrrolate.

Heart rate, systolic, diastolic, and mean arterial pressure, and peripheral oxygen saturation were recorded every minute from the start of induction until tracheal intubation and at 1,2, and 5 min after tracheal intubation (secondary endpoints).

\section{Statistical analysis}

Previous studies have estimated the incidence of EIM to be around 50\% [1-3]. The sample size calculated for a 5\% level of significance and power of $80 \%$ was 57 in each group, assuming that the proportion of patients who developed myoclonus after slow injection or pre-treatment with etomidate would be $25 \%$. Assuming a $10 \%$ dropout rate, the total sample size was set at 189 (a minimum of 63 in each group).

Statistical analysis was performed using SPSS for Windows, version 17.0 (SPSS Inc., USA). Continuous variables-age, weight, induction dose, LOC dose, LOC time, duration of surgery, heart rate and blood pressure-are presented as mean (SD), and categorical variables-American Society of Anesthesiologists (ASA) class, sex distribution, myoclonus incidence, severity grade, and time of onset noted as occurrence of myoclonus within a categorical time frame ( $1 \mathrm{~min}, 1$ to $2 \mathrm{~min}$, and 2 to 3 min) - are presented as absolute numbers or percentages with 95\% CI. The continuous data were first checked for normality using the Shapiro-Wilk test. All the continuous variables were found to be normally distributed. Therefore, all these variables were compared across the three groups using ANOVA. The F-values were found statistically insignificant for all continuous variables except LOC dose and LOC time. Tukey's multiple comparisons test was used for intergroup comparisons for LOC dose, as the variances were homogenous. Tamhane's T2 test was used for intergroup comparisons for LOC time, as the variances were not homogenous. Categorical variables were analyzed using the chi-square test. For all statistical tests, $\mathrm{P}<0.05$ was taken to indicate a significant difference.

\section{Results}

There were no significant differences in demographic profile, the mean duration of surgery, or dose of etomidate required for induction among the groups (Table 1).

The mean LOC dose was significantly lower in Group $S$ than in Group P and Group C. There was no difference in mean LOC dose between Group P and Group C. The mean time until LOC in Group S was significantly longer than that in Group $\mathrm{C}$ and Group P. There was no difference in mean time until LOC between Group P and Group C (Table 1).

Table 1. Demographic Profile, Induction Characteristics, and Surgical Duration for Each Study Group

\begin{tabular}{|c|c|c|c|c|}
\hline & Group C $(n=63)$ & Group P $(n=63)$ & Group S $(n=63)$ & $P$ value \\
\hline Age (yr) & $33.6(12.4)$ & $34.1(13.1)$ & $34.6(10.8)$ & 0.895 \\
\hline $\operatorname{Sex}(M / F)$ & $19 / 44$ & $26 / 37$ & $25 / 38$ & 0.377 \\
\hline Weight (kg) & $54.1(12.7)$ & $61.6(35.9)$ & $55.6(11.4)$ & 0.160 \\
\hline ASA class (I/II) & $55 / 8$ & $54 / 9$ & $54 / 9$ & 0.956 \\
\hline Induction dose (mg) & $15.9(3.6)$ & $16.4(3.1)$ & $16.7(3.4)$ & 0.456 \\
\hline LOC dose (mg) & $15.9(3.6)$ & $16.4(3.1)$ & $10.8(3.4)$ & $<0.001$ \\
\hline LOC time $(\mathrm{s})$ & $29.2(6.8)$ & $33.4(8.5)$ & $79.9(23.1)$ & $<0.001$ \\
\hline Duration of surgery (min) & $125.6(61.2)$ & $110.4(56.5)$ & $123.7(66.5)$ & 0.324 \\
\hline
\end{tabular}

Values are mean (SD) or number. Group C: control group, Group P: priming group, Group S: slow injection group. ASA: American Society of Anesthesiologists, LOC dose: loss of consciousness dose, Group S vs. Group P $(\mathrm{P}<0.001)$, Group S vs. Group C $(\mathrm{P}<0.001)$, Group P vs. Group C $(\mathrm{P}=$ 0.701). LOC time: loss of consciousness time, Group S vs. Group P $(\mathrm{P}<0.001)$, Group S vs. Group C $(\mathrm{P}<0.001)$, Group $\mathrm{P}$ vs. Group C $(\mathrm{P}=0.240)$. 
Table 2. Characteristics of Myoclonus in Each Study Group

\begin{tabular}{lcccc}
\hline \multicolumn{1}{c}{ Myoclonus } & $\begin{array}{c}\text { Group C } \\
(\mathrm{n}=63)\end{array}$ & $\begin{array}{c}\text { Group P } \\
(\mathrm{n}=63)\end{array}$ & $\begin{array}{c}\text { Group S } \\
(\mathrm{n}=63)\end{array}$ & P value \\
\hline Incidence & $53(84.1)$ & $38(60.3)$ & $49(77.8)$ & 0.007 \\
Severity grade & & & & 0.016 \\
0 (none) & $10(15.9)$ & $25(39.7)$ & $14(22.2)$ & \\
1 (mild) & $10(15.9)$ & $15(23.8)$ & $17(27.0)$ & \\
2 (moderate) & $22(34.9)$ & $13(20.6)$ & $17(27.0)$ & \\
3 (severe) & $21(33.3)$ & $10(15.9)$ & $15(23.8)$ & \\
Time of onset (min) & & & & 0.040 \\
$0-1$ & 23 & 8 & 16 & \\
$1-2$ & 21 & 19 & 20 & \\
$2-3$ & 9 & 7 & 7 & \\
$>3$ & 0 & 4 & 6 &
\end{tabular}

Values are number of patients (\%). Group C: control group, Group P: priming group, Group S: slow injection group. Incidence of myoclonus, Group P vs. Group C ( $\mathrm{P}=0.003)$, Group P vs. Group S $(\mathrm{P}=0.034)$, Group $S$ vs. Group C $(P=0.364)$. Severity grade of myoclonus (moderate or severe), Group C vs. Group P $(\mathrm{P}<0.001)$, Group C vs. Group S (P = $0.046)$, Group P vs. Group $S(P=0.106)$. Time of onset of myoclonus, Group C vs. Group P $(\mathrm{P}=0.025)$, Group C vs. Group S $(\mathrm{P}=0.061)$, Group $P$ vs. Group $S(P=0.630)$. Time of onset $>3$ min: number of patients who had myoclonus after 3 min observation period was over (before the effect of muscle relaxant).

The incidence, severity, and time of onset of myoclonus in the three groups were as shown in Table 2. The incidence of myoclonus was significantly lower in Group P (60.3\%, 95\% CI: 48.0-71.5) than in Group C (84.1\%, 95\% CI: 72.9-91.3, P $=0.003)$ and Group S (77.8\%, 95\% CI: 66.0-86.4, P = 0.034). There was no significant difference in the incidence of myoclonus between Groups $\mathrm{C}$ and $\mathrm{S}(\mathrm{P}=0.364)$.

A moderate or severe grade of EIM (Grade 2 or 3) was observed in a significantly greater number of patients in Group C than in Group P and Group S. However, no significant difference in the number of patients experiencing moderate to severe EIM was observed between Group P and Group S.

The time of onset of myoclonus, defined by the occurrence of myoclonus within the previously specified time frames was as shown in Table 2. Myoclonus occurred within $2 \mathrm{~min}$ from the start of induction in $44 / 53$ patients (83.0\%), 36/49 patients (73.5\%), and 27/38 patients (71.1\%) in Groups C, S, and P respectively, with no significant differences between the groups. Myoclonic movement was observed beyond the 3-min time frame of observation in four patients in Group P and six patients in Group S (Table 2).

Hemodynamic parameters such as mean arterial lpressure (Fig. 2) and heart rate (Fig. 3) were comparable across the three groups. None of the patients showed any incidence of oxygen desaturation.

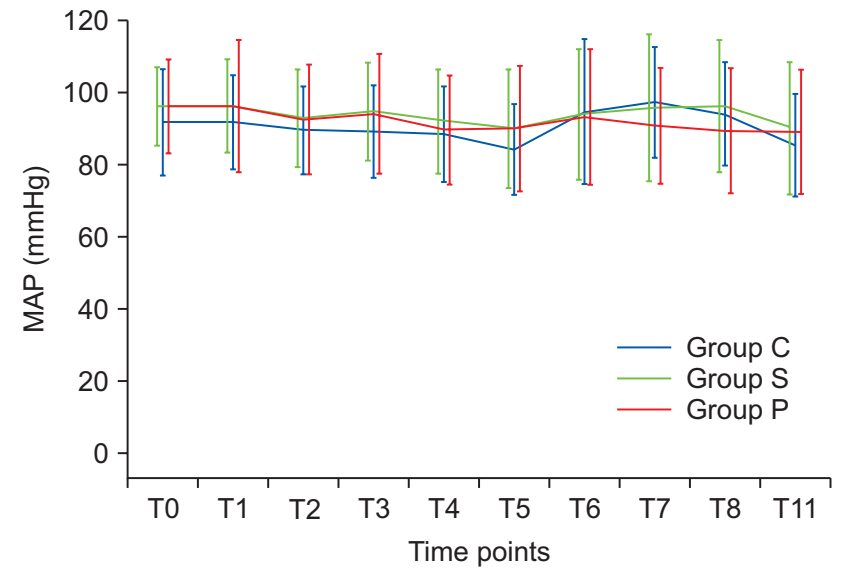

Fig. 2. Mean arterial pressure (MAP) changes at various time points in the three study groups. T0 is the baseline reading; T1, T2, T3, T4, and T5 are readings at $1,2,3,4$, and 5 min respectively from the start of induction. T6 is at tracheal intubation. T7, T8, and T11 are readings at 1 , 2 , and 5 min respectively after intubation.

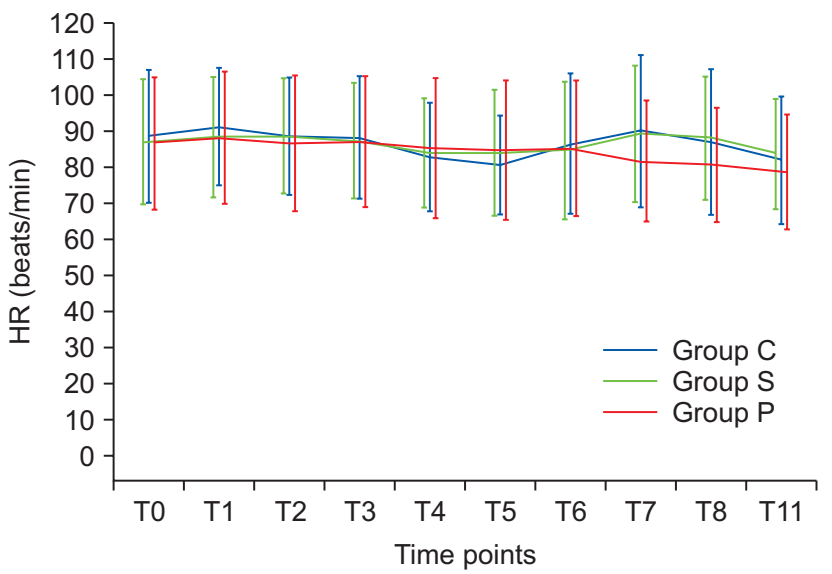

Fig. 3. Heart rate (HR) changes at various time points in the three study groups. T0 is the baseline reading; $\mathrm{T} 1, \mathrm{~T} 2, \mathrm{~T} 3, \mathrm{~T} 4$, and $\mathrm{T} 5$ are readings at $1,2,3,4$, and 5 min respectively from the start of induction. T6 is at tracheal intubation. T7, T8, and T11 are readings at 1,2 , and 5 min respectively after intubation.

\section{Discussion}

In the present study, we found that a small priming dose $(0.03$ $\mathrm{mg} / \mathrm{kg}$ ) of etomidate given prior to the induction dose was more effective than slow injection of etomidate (over $2 \mathrm{~min}$ ) in reducing the incidence of EIM.

The involuntary myoclonic movements seen with etomidate are believed to be caused by subcortical disinhibition [1]. A large dose of etomidate depresses the cortical activity before depressing subcortical activity, thereby causing myoclonus $[8,12,13]$. Both pretreatment (priming) with etomidate and slow administration may prevent the unsynchronized onset of drug action 
at different sites within the central nervous system that may be responsible for EIM [1,4].

In our study, the incidence of EIM in the priming group was significantly lower than in the control and slow injection groups. There was no significant difference in the incidence of EIM between the control and slow injection groups. The incidence of $84.1 \%$ (53/63 patients) EIM in the control group in our study is comparable to the results of other studies $[2,10]$. Aissaoui et al. [2] observed a significant reduction in the incidence of EIM following pretreatment with a low dose of etomidate (priming dose). In their study, $26 \%$ (6/23 patients) of patients in the priming group experienced myoclonus as compared to $87 \%(20 / 23$ patients) in the control group $(\mathrm{P}<0.001)$. Doenicke et al. [1], in a crossover study involving eight patients, found that the incidence of EIM was 25\% (2/8 patients) when etomidate induction followed pretreatment with $0.05 \mathrm{mg} / \mathrm{kg}$ etomidate, as compared to $75 \%$ (6/8 patients) in the control group. In another study, three different pretreatment doses of etomidate were compared. The incidence of EIM was found to be $20 \%$ (4/20 patients), $25 \%$ (5/20 patients), and 35\% (7/20 patients) for pretreatment with $0.03,0.05$, and $0.075 \mathrm{mg} / \mathrm{kg}$ etomidate, respectively [1]. We found a higher incidence of EIM in the priming group than reported by the other studies [1,2]. This could perhaps be a result of the fact that we did not premedicate our patients and administered a muscle relaxant at $180 \mathrm{~s}$ after the start of induction, thus allowing a longer time period for observation of myoclonus. In contrast, Doenicke et al. [1] premedicated their patients with oral midazolam $1 \mathrm{~h}$ prior to induction and administered a muscle relaxant at $90 \mathrm{~s}$ after induction, allowing a shorter time period for observation than ours. Aissaoui et al. [2] also used a smaller time period for observation, as they administered a muscle relaxant at $60 \mathrm{~s}$ after induction with etomidate.

Do et al. [4] observed that slow injection of etomidate (over $2 \mathrm{~min})$ resulted in a significantly lower incidence of EIM $(28 \%$ [7/25 patients]) than giving it as a fast injection over $10 \mathrm{~s}(84 \%$ [21/25 patients], $\mathrm{P}<0.001)$. Even though our study methodology was similar to that of Do et al., we observed a higher incidence (77.8\% [49/63 patients]) of EIM in the slow injection group. This difference could perhaps be attributed to the fact that our study population was younger (mean [SD] age, 34.6 [10.8] vs. 52 [14] years). The age of a patient affects the risk of myoclonus: the younger the patient, the higher the risk [5].

We found that the percentage of patients who experienced moderate or severe EIM was significantly lower in the priming and slow injection groups than in the control group. Aissaoui et al. [2] also found the severity of myoclonus to be significantly lower with priming than in a control group. Do et al. [4] found the severity of myoclonus to be significantly lower in a slow injection group than in a fast injection group. We found no significant difference in the severity of myoclonus between the prim- ing and slow injection groups. To the best of our knowledge, no study has compared the effects of priming vs. slow injection of etomidate on the incidence of EIM. We are hence unable to compare our results with those of other authors.

Do et al. [4] noted that in their slow injection group, in contrast with the fast injection group, LOC occurred before the complete induction dose was administered. This finding implies the possibility of a smaller dose requirement in the slow injection group [4]. In our study, the mean time until LOC was significantly longer in Group S than in Group C and Group P. By the time LOC occurred in Group S, only 10.8 (3.4) mg of etomidate had been administered, while the complete induction dose was 16.7 (3.4) mg. On the other hand, in the priming and control groups, the complete induction dose was administered before LOC was observed. The occurrence of EIM is dose-related, larger doses being associated with a higher incidence [1]. Had etomidate been administered until the onset of LOC, instead of as at a fixed dosage, it is possible that the incidence of EIM would have been reduced in the slow injection group.

In the majority of the patients in all our study groups, the onset of myoclonus occurred within 2 min after the start of induction. However, four patients in the priming group and six patients in the slow injection group had myoclonus after 3 min from the start of induction. The period of observation for myoclonus varied from 1 to $3 \mathrm{~min}$ in most previous studies, suggesting that the actual incidence of EIM may be higher than that reported. Delayed myoclonic movements could go undetected due to masking by a neuromuscular blockade. To determine the true incidence of EIM, further studies are needed to identify the optimal observation period.

Our study has several limitations. First, it was not a blind study. Due to the variable speed of injection ( 2 min vs. $20 \mathrm{~s}$ ) of etomidate in the study groups, it was not possible to blind either the physicians or the patients. Second, the time of onset of myoclonus was categorized into 1-min intervals from the start of induction. Thus, the exact time of onset and duration of myoclonus were not noted.

To conclude, we found that priming with etomidate significantly reduces the incidence and severity of myoclonus. Priming is more effective than slow injection in reducing the incidence of myoclonus, but their effects on the severity of myoclonus are comparable.

\section{Funding Statement}

No funding received. All expenses were borne by Vardhman Mahavir Medical College and Safdarjung Hospital. 
ORCID

Parul Mullick, https://orcid.org/0000-0003-4384-3377

Vandana Talwar, https://orcid.org/0000-0003-1009-8315
Shipra Aggarwal, https://orcid.org/0000-0003-2709-1486

Smita Prakash, https://orcid.org/0000-0002-5299-2107

Mridula Pawar, https://orcid.org/0000-0002-7052-7751

\section{References}

1. Doenicke AW, Roizen MF, Kugler J, Kroll H, Foss J, Ostwald P. Reducing myoclonus after etomidate. Anesthesiology 1999; 90: 113-9.

2. Aissaoui Y, Belyamani L, El Wali A, Idrissi Hajjouji SM, Atmani M, Drissi Kamili N. Prevention of myoclonus after etomidate using a priming dose. Ann Fr Anesth Reanim 2006; 25: 1041-5.

3. Giese JL, Stockham RJ, Stanley TH, Pace NL, Nelissen RH. Etomidate versus thiopental for induction of anesthesia. Anesth Analg 1985; 64: 871-6.

4. Do SH, Han SH, Park SH, Kim JH, Hwang JY, Son IS, et al. The effect of injection rate on etomidate-induced myoclonus. Korean J Anesthesiol 2008; 55: 305-7.

5. Singh KA, Ruchi G, Singh AK, Kaur BT. Efficacy of lignocaine versus midazolam in controlling etomidate-induced myoclonus: a randomized placebo-controlled study. Ain-Shams J Anaesthesiol 2014; 7: 460-4.

6. Berry JM, Merin RG. Etomidate myoclonus and the open globe. Anesth Analg 1989; 69: 256-9.

7. Gultop F, Akkaya T, Bedirli N, Gumus H. Lidocaine pretreatment reduces the frequency and severity of myoclonus induced by etomidate. J Anesth 2010; 24: 300-2.

8. Schwarzkopf KR, Hueter L, Simon M, Fritz HG. Midazolam pretreatment reduces etomidate-induced myoclonic movements. Anaesth Intensive Care 2003; 31: 18-20.

9. Un B, Ceyhan D, Yelken B. Prevention of etomidate-related myoclonus in anesthetic induction by pretreatment with magnesium. J Res Med Sci 2011; 16: 1490-4.

10. Isitemiz I, Uzman S, Toptaş M, Vahapoglu A, Gül YG, Inal FY, et al. Prevention of etomidate-induced myoclonus: which is superior: fentanyl, midazolam, or a combination? A Retrospective comparative study. Med Sci Monit 2014; 20: 262-7.

11. Luan HF, Zhao ZB, Feng JY, Cui JZ, Zhang XB, Zhu P, et al. Prevention of etomidate-induced myoclonus during anesthetic induction by pretreatment with dexmedetomidine. Braz J Med Biol Res 2015; 48: 186-90.

12. Helmers JH, Adam AA, Giezen J. Pain and myoclonus during induction with etomidate. A double-blind, controlled evaluation of the influence of droperidol and fentanyl. Acta Anaesthesiol Belg 1981; 32: 141-7.

13. Van Keulen SG, Burton JH. Myoclonus associated with etomidate for ED procedural sedation and analgesia. Am J Emerg Med 2003; 21: 556-8. 